\title{
Using the latest resistance score to predict etravirine (ETV) resistance in naïve and NNRTI-failing patients
} M Zaccarelli*1, P Lorenzini ${ }^{1}$, CSF Ceccherini-Silberstein ${ }^{2}$, V Tozzi ${ }^{1}$, F Forbici ${ }^{3}$,

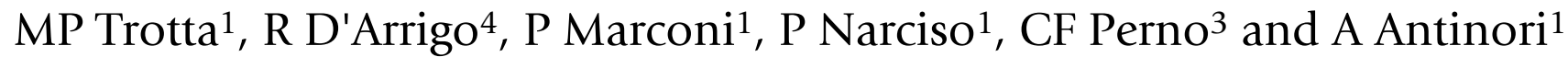

Address: ${ }^{1}$ National Institute for Infectious Diseases "Lazzaro Spallanzani", Clinical Department, Rome, Italy, ${ }^{2}$ Department of Experimental Medicine, University of Rome "Tor Vergata", Rome, Italy, ${ }^{3}$ National Institute for Infectious Diseases "Lazzaro Spallanzani", Virological Department, Rome, Italy and ${ }^{4}$ National Institute for Infectious Diseases, Rome, Italy

* Corresponding author

from Ninth International Congress on Drug Therapy in HIV Infection

Glasgow, UK. 9-13 November 2008

Published: 10 November 2008

Journal of the International AIDS Society 2008, I I (SuppI I):PI79 doi:I0.I I86/I758-2652-II-SI-PI79

This abstract is available from: httP://Www.jiasociety.org/content/II/SI/PI79

(C) 2008 Zaccarelli et al; licensee BioMed Central Ltd.

\section{Purpose of the study}

To assess the feasibility of a rescue ETV-containing cART regimen in naïve patients with primary NNRTI resistance mutations or after first NNRTI failure, using the latest resistance score presented.

\section{Methods}

A set of 17 mutations (V90I, A98G, L100I, K101E/H/P, V106I, E138A, V179D/F/T, Y181C/I/V, G190A/S, M230L) were found associated with ETV resistance in the Phase III DUET-1 and DUET-2 trials. Recently, a different score was assigned to each mutation (i.e. Y181C/I have the highest score: 3 ). An overall score of $\leq 4$ was associated with reduced response and a score between 2.5-3.5 with intermediate response (reference). ETV resistance was calculated from a large database of patients undergoing genotypic resistance test.

\section{Results}

Overall, 241 ARV-naïve patients and 311 failing a first NNRTI regimen $(\mathrm{EFV}=189, \mathrm{NVP}=122)$ were analyzed. Among naïve patients, $14(5.8 \%)$ harbored $\leq 1$ major NNRTI resistance mutation but only in one patient $(0.4 \%)$ a $\leq 4$ score, and in five patients $(2.1 \%)$ a score between 2.5-3.5 were detected.

Among failing patients, two-thirds harbored major NNRTI mutations (about half had K103N). In contrast, a $\leq 4$ score was found in $5.8 \%$ of patients, with similar pro- portion in EFV- and NVP-treated patients (5.8\% vs. 5.7\%), though among NVP patients a score between 2.5-3.5 was more frequently found (28.7\% vs. $20.1 \%$ ).

The probability of developing a $\leq 4$ score was $0.0 \%$ during the first 3 months of NNRTI failure and 3.1\% between 36 months (2.6\% in EFV vs. 3.9\% in NVP failure). Subsequently, during EFV failure, the probability of developing a $\leq 4$ score increased between 6-12 months to $20.0 \%$ (particularly between 9-12 months: $23.5 \%$ ) and during NVP failure, between 9-12 months to $9.1 \%$.

At adjusted logistic regression, remaining in NNRTI failure between 6-12 months was the only factor associated to developing a $\leq 4$ ETV score (OR: 22.0, 95\& CI: 2.65182.89, $\mathrm{p}=0.004)$.

\section{Conclusion}

The presence of mutations predictive of full or intermediate ETV resistance is uncommon among naïve patients, thus, in almost all cases, ETV use may be allowed. The detection of ETV-resistance is also infrequent in patients failing a NNRTI regimen because usually they develop the K103N mutation, that alone or in combination does not affect ETV sensitivity. Our data also suggest that a quick withdrawal of a failing NNRTI regimen, possibly in the first 3 months of failure, can maintain ETV sensitivity, thus preserving a treatment option. 


\section{References}

I. Vingerhoets ], et al:: An update of the list of NNRTI mutations associated with decreased virological response to etravirine: multivariate analysis of the pooled DUET-I and DUET-2 clinical trial data. [XVII International Drug Resistance Workshop, June 10-14, Sitges, Spain; Abstract 24]. Antivir Therapy 2008, I3(Suppl 3):A26.

Publish with Bio Med Central and every scientist can read your work free of charge

"BioMed Central will be the most significant development for disseminating the results of biomedical research in our lifetime. " Sir Paul Nurse, Cancer Research UK

Your research papers will be:

- available free of charge to the entire biomedical community

- peer reviewed and published immediately upon acceptance

- cited in PubMed and archived on PubMed Central

- yours - you keep the copyright

Submit your manuscript here:

http://www.biomedcentral.com/info/publishing_adv.asp 